\title{
Unpalatable plants facilitate tree sapling survival in wooded pastures
}

\author{
CHRISTIAN SMIT,* JAN DEN OUDEN† and HEINZ MÜLLER-SCHÄRER* \\ *Department of Biology, Unit of Ecology and Evolution, University of Fribourg, Chemin du Musée 10, CH-1700 \\ Fribourg, Switzerland; and $\dagger$ Centre for Ecosystem Studies, Forest Ecology and Forest Management Group, \\ Wageningen University, PO Box 47,6700 AA Wageningen, the Netherlands
}

\section{Summary}

1. In endangered wooded pasture ecosystems established tree saplings are frequently found in spatial association with protective structures, suggesting nurse effects. This associational resistance is thought to be a driving force behind tree regeneration in wooded pastures. Experimental evidence for associational resistance is, however, scarce. We studied the effects of unpalatable plants on tree sapling performance in a wooded pasture ecosystem in Switzerland and tested the associational resistance hypothesis experimentally.

2. We transplanted 600 Picea abies saplings of two size classes $(5 \mathrm{~cm}$ and $10 \mathrm{~cm})$ in plots: (i) with unpalatable plants (either Gentiana lutea or Cirsium acaule, representing a chemically and mechanically defended species, respectively); (ii) with one of both unpalatable plants clipped to the ground; and (iii) without any unpalatable plants. Grazing intensity was measured once in each plot and tree sapling performance was followed for 2 consecutive years.

3. Grazing intensity was significantly higher in plots without unpalatable plants, and significantly higher in plots with Cirsium than with Gentiana. Correspondingly, sapling survival (21.5\% and $10 \cdot 6 \%$ after 1 and 2 grazing years, respectively) was significantly higher near unpalatable plants, and significantly higher in plots with Gentiana than with Cirsium. Large tree saplings survived significantly better than small ones, and depended less on the unpalatable plants for survival.

4. Except for saplings planted near Gentiana, sapling removal by cows and horses was the major cause of death, the extent varying between unpalatable species and treatments. 5. The growth in height of the saplings was unaffected by the treatments.

6. Synthesis and applications. This study shows that unpalatable plants can enhance tree regeneration in wooded pastures. Sapling survival was significantly higher near unpalatable plants where grazing intensity was significantly lower. Protection against cattle is particularly important for small saplings. These results have important management implications for the endangered and disappearing wooded pastures in western Europe. Transplanting tree saplings near unpalatable plants could be an alternative reforestation technique in intensively grazed wooded pastures. On the other hand, removal of unpalatable plants and shrubs might prevent or slow down undesired tree encroachment in less intensively grazed areas.

Key-words: associational resistance, cattle, Cirsium acaule, Gentiana lutea, grazing, Picea abies, tree regeneration

doi: 10.1111/j.1365-2664.2006.01147.x

Correspondence: Christian Smit, Departamento de Ciencias Ambientales, Facultad de Ciencias del Medio Ambiente, Universidad de Castilla-La Mancha, E-45071 Toledo, Spain (fax +34925 2688 40; e-mail christian.smit@uclm.es).

\section{Introduction}

An increasing number of studies have indicated that positive interactions among plant species may drive community function and structure in various ecosystems. 
Recent examples come from ecosystems such as high mountain vegetations (Nunez, Aizen \& Ezcurra 1999; Choler, Michalet \& Callaway 2001), deserts (Munzbergova \& Ward 2002), forests (Arevalo \& Fernandez-Palacios 2003) and pastures (Callaway, Kikvidze \& Kikvidze 2000). Such spatial associations suggest facilitative effects, as one species directly or indirectly ameliorates the environment of the other. Understanding such interactions between plants helps to clarify the structure, diversity and dynamics of plant communities and ecosystems (Castro, Zamora \& Hodar 2002). So far, most evidence for these facilitative interactions between plants comes from descriptive studies, and empirical evidence is rare but needed, especially for grazed ecosystems (Callaway, Kikvidze \& Kikvidze 2000).

Wooded pastures are traditional semi-natural ecosystems, extensively grazed and logged, with natural regeneration of both grassland and woodland. Today, they are among the most endangered ecosystems in Europe, threatened by both intensification and abandonment of management. Wooded pastures have probably been developed by humans since Neolithic times (Pott \& Hüppe 1991) but others suggest a natural origin via now extinct large herbivores as Bos primigenius and Equus ferus (Vera 2000). Remnants of this onceabundant system are nowadays well known for their high conservation values, and serve as examples for nature development projects in western Europe, where large herbivores are increasingly reintroduced in former agricultural areas in order to increase biodiversity (Olff et al. 1999). While an understanding of the mechanisms regulating biodiversity maintenance is a prerequisite for sustainable management in these systems, it is often lacking.

It has been proposed that facilitation by grazingresistant plants, also known as associational resistance (Bakker et al. 2004), associational avoidance (Milchunas \& Noy-Meir 2002) and defence guilds (Atstatt \& Odowd 1976), is one of the processes driving tree establishment in wooded pastures (Olff et al. 1999; Bokdam \& Gleichman 2000). Various studies (Rousset \& Lepart 1999; Kuiters \& Slim 2003; Vera 2000; Smit et al. 2005) report spatial associations between young trees and unpalatable plants, possibly indicating establishment of trees via facilitator species, but empirical evidence for associational resistance in these systems is scarce (Pages \& Michalet 2003; Tirado \& Pugnaire 2003). Furthermore, factors affecting associational resistance between tree saplings and unpalatable plants are largely unknown.

Plants have evolved various traits against herbivory, such as chemical, morphological and phenological defence mechanisms, and these vary in their effectiveness (Crawley 1983). As a consequence, the survival probability of spatially associated tree saplings may depend on the effectiveness of the facilitator's defence strategy and vary among facilitator plants with different defence mechanisms.

Sapling size affects the probability of being grazed by herbivores, with small tree saplings less likely to be discovered by herbivores and therefore less likely to be damaged (Rao et al. 2003). Consequently, small tree saplings may need less protection against browsing than larger tree saplings. Alternatively, large tree saplings may be easier to detect and hence avoided (when not palatable to herbivores), in contrast with small tree saplings which may be grazed accidentally together with surrounding, preferred vegetation. Thus, associational resistance may depend on the size of the tree sapling.

Tree saplings growing near unpalatable plants may be protected effectively against cattle grazing but could suffer more from competition with their facilitators (for light, nutrients, water, etc.) than tree saplings growing in open swards or grassland (Berkowitz, Canham \& Kelly 1995; Rousset \& Lepart 2000). Accordingly, growth of protected tree saplings may be reduced as a result of competition with their facilitators, leading to a trade-off between protection against grazers and being limited in growth by unpalatable plants.

In this field study we tested the proposed facilitative effects of a physically and chemically defended unpalatable species on tree sapling performance. We transplanted Picea abies (L.) Karst. saplings of two size classes in plots with and without unpalatable plants, and in plots with unpalatable plants removed to ground level. Tree sapling performance was followed throughout two grazing seasons. In accordance with the associational resistance theory, we hypothesized that tree saplings planted in plots with unpalatable plants would have higher survival but reduced growth rates. Furthermore, we expected to find differences in protective effects of the two unpalatable species and different performances of the two size classes of tree saplings.

\section{Methods}

\section{STUDY AREA}

This study was conducted in the Swiss Jura Mountains. The climate is generally continental with Atlantic influences. Mean yearly temperature varies between $3{ }^{\circ} \mathrm{C}$ and $5^{\circ} \mathrm{C}$. Annual precipitation lies between $1400 \mathrm{~mm}$ and $2000 \mathrm{~mm}$ in this region (with a peak in summer) but soils are considered to be relatively dry because of the high permeability of the underlying calcareous bedrock. Our study site $\left(6^{\circ} 12^{\prime} \mathrm{N}, 46^{\circ} 32^{\prime} \mathrm{E}\right)$ is a wooded pasture of approximately 12 ha at an altitude of $1340 \mathrm{~m}$ a.s.1. It is a typically species-rich grassland of the Mesobrometum type, with scattered individuals or small groups of $P$. abies trees and mean tree cover of c. $40 \%$. The study site is situated in the Pré-aux-Veaux, an extensively grazed wooded pasture area (102 ha) belonging to the larger Parc Jurassien Vaudois. The area is typically grazed from early June until early October according to a rotation system, with three to four grazing rotations per year, each lasting approximately 10 days. The average herd consists of c. 58 heifers, occasionally including five to 10 horses at the end of the grazing season. Because of the extreme hot weather 
conditions during the first year (2003), the third grazing rotation was extended and fences between paddocks were opened in order to enlarge the grazed area (in this case 110 ha grazed for 33 days).

Naturally occurring large vertebrate herbivores in the site are rarely seen but include roe deer Capreolus capreolus L. and mountain hare Lepus timidus L.

\section{TRANSPLANTATION EXPERIMENT}

Our experiment was conducted with 600 1- and 2-yearold $P$. abies saplings, which were obtained from a local tree nursery. Seed material originated from a site in the Swiss Jura Mountains at $1400 \mathrm{~m}$ a.s.1. near the study site. In autumn 2002 the tree saplings were taken from their plant beds and put in plastic trays (individual pot per tray $3 \times 3 \times 6 \mathrm{~cm}$ ) filled with nutrient-rich peaty soil, after the taproots were cut back to $5 \mathrm{~cm}$ to stimulate root growth. The saplings over-wintered outside in the trays, protected from severe frost by a thick leaf layer of $\pm 15 \mathrm{~cm}$.

We selected Gentiana lutea L. and Cirsium acaule Scop. as unpalatable plants. Gentiana and Cirsium, measuring between 50 and $120 \mathrm{~cm}$ and 10 and $30 \mathrm{~cm}$ in height, respectively, are both perennial species from calcareous mountain grasslands and occur commonly in wooded pastures in the Swiss Jura Mountains. Cattle generally avoid these plants (C. Smit, personal observation) because they contain toxic elements (Gentiana) or are spiny (Cirsium). Naturally established tree saplings of $P$. abies have been found to be positively associated with both species, indicating nurse effects (Smit et al. 2005).

We randomly selected an equal number of plots (c. 200) with Gentiana and Cirsium or without any unpalatable plant (or shrub, rocky outcrop or tree) within a $1 \cdot 5-\mathrm{m}$ radius around the plot. The Gentiana and Cirsium plots contained more than one shoot (ramet) with patch sizes measuring $c .30 \mathrm{~cm}$ and $20 \mathrm{~cm}$, respectively. Half of the plots with Gentiana and Cirsium were randomly selected for a clipping treatment: canopies of the unpalatables were removed by cutting the stems at soil level (leaving surrounding vegetation intact). This was repeated periodically during the season because of regrowth of the plants. The cutting treatment was added to test for the potential effects of environmental conditions (litter, soil structure, etc.) other than those relating to changes in the microclimate under the canopy. All 600 plots were at least $1.5 \mathrm{~m}$ apart and were distributed evenly over the entire study site in order to avoid spatial clumping.

In May 2003, all 1- and 2-year-old Picea saplings were transplanted in the selected plots: (i) near either Gentiana or Cirsium at $\pm 10 \mathrm{~cm}$ from their stem; (ii) near the cut Gentiana or Cirsium; and (iii) with no unpalatable plant nearby. Each possible combination between unpalatable species (2), treatment (3) and sapling size (2) was repeated 50 times. Tree saplings that died during the 2 weeks following transplantation (29 in total, most probably because of a severe spring frost on 15 May) were replaced with new saplings in the original positions. At the start of the experiment (31 May) the 1- and 2-yearold saplings measured $4.85 \mathrm{~cm}( \pm 1 \cdot 57)$ and $10 \cdot 12 \mathrm{~cm}$ $( \pm 3 \cdot 81)$, respectively (means $\pm \mathrm{SD})$. The average vegetation height during the grazing seasons was $5 \mathrm{~cm}$ (data not shown) so we assumed that the 1-year-old-saplings (hereafter called small) would be less apparent than the 2-year-old saplings (hereafter called large).

\section{MEASUREMENTS}

Grazing intensity was measured after the first grazing rotation period in 2003 , by estimating the percentage cover of grazed and cropped shoots or shoot tips in a $40-\mathrm{cm}$ circle around the plot. Shoots of Gentiana and Cirsium were excluded for this estimation.

Tree sapling performance was followed for two consecutive grazing seasons (2003 and 2004). Measurements on the tree saplings were carried out six times in total by the same person: before the first cattle arrival (i); after each rotation period of the first season (ii, iii and iv); before cattle arrival for the second season (v); and at the end of the second grazing season (vi). Each time presence-absence of the saplings, their height (from ground level to the highest green needle) and survival were recorded. Saplings were recorded as dead when there was no more visible chlorophyll. In the first season, we distinguished between dead standing and removed tree saplings: tree saplings that were not found back at their original planting position (absent) were considered removed by the cows and, hence, dead. Tree saplings that were not removed by the cows but dead standing were recorded as present and dead. We considered removal of tree saplings as the most direct effect of cattle grazing, whereas the performance of non-removed tree saplings could depend on various direct and indirect effects of cattle as well as microenvironmental conditions. In the second grazing season, dead standing and removed saplings could not be distinguished because many rotted away during winter, so only tree sapling survival was recorded.

\section{ANALYSES}

Differences in grazing intensity between unpalatable species, sapling sizes and treatments were tested using ANOVA. The response variable grazing intensity was $\log 10(x+1)$ transformed to satisfy the assumptions for normality. We used Tukey HSD tests for comparing pairs of group means of significant variables.

Cox regression was used to analyse and compare the effects of the treatments on survival of the tree saplings over the entire range of the study period ( 2 years). The start of the experiment was set at 31 May 2003 and measurements were taken at 52, 66, 129, 373 and 498 days. For all the tree saplings that died a 'mid-time' value was calculated, in order to approximate time of death. This was done by taking the average between 
time of first death observation and the previous census (when the sapling was still alive), resulting in 26, 59, 98, 251 and 436 days.

In order to analyse the effects of the three categorical predictors (treatment, species and sapling size) on sapling survival after one and two grazing seasons, we fitted generalized linear models (GLM) to our data with a binomial error distribution and a logit link function. The predictor variables size (two), species (two) and treatment (three) were added sequentially, including all possible two- and three-way interactions. Chi-square statistics were used for the calculation of the significance of the factors in the models. We used Bonferronicorrected tests for comparing group means of significant variables and interactions.

With the aim of assessing the importance of sapling removal as cause of death (only after first grazing season), we analysed the ratio of removed to dead saplings (number of removed saplings out of a total of 467 dead saplings) using a GLM with a binomial error distribution and a logit link function. Again, we added the predictor variables size, species, treatment and interactions sequentially, and we used chi-square statistics for the calculation of significance. We applied Bonferroni corrections to tests for multiple comparisons of group means of significant variables and interactions.

We calculated the relative sapling growth by subtracting the initial height from the final height (end of first or second grazing season), divided by the initial height. ANOVA, SS type III, was used to test for differences in sapling growth between treatments and species after the first and second grazing seasons. The response variables were $\log 10(x+1)$ transformed prior to the analysis to improve normality of the errors. Species, treatment and their interaction were used as fixed factors in the models. Only surviving saplings were selected for this analysis, leading to a total of 125 and 61 individuals for the first and second years, respectively.

We used Genstat 7 for the GLM and SPSS release $11 \cdot 5$ for all other analyses.

\section{Results}

\section{GRAZING INTENSITY}

Results of the ANOVA on grazing intensity showed significant differences between the two unpalatable species and the three treatments, but not between the sapling sizes (Table 1). Tukey HSD tests showed that grazing was generally lowest in plots with unpalatable plants, higher in plots with cut unpalatable plants and highest in plots without unpalatables (Fig. 1). Further, grazing intensity was significantly higher in plots with uncut Cirsium than in plots with uncut Gentiana.

\section{TREE SAPLING PERFORMANCE}

The number of surviving tree saplings declined from 600 at the start of the experiment to $451(74 \cdot 1 \%), 325$
Table 1. Results of ANOva for the effects of species, size and treatment and interactions on estimated grazing intensity $(\log 10(x+1)$ transformed) in a 40 -cm circle around the tree saplings

\begin{tabular}{lrrrl}
\hline Source & d.f. & \multicolumn{1}{c}{ MS } & \multicolumn{1}{l}{$F$} & $P$ \\
\hline Species & 1 & $7 \cdot 43$ & $26 \cdot 85$ & $0 \cdot 000$ \\
Size & 1 & $0 \cdot 07$ & $0 \cdot 24$ & $0 \cdot 623$ \\
Treatment & 2 & $11 \cdot 41$ & $41 \cdot 25$ & $0 \cdot 000$ \\
Species $\times$ size & 1 & $0 \cdot 13$ & $0 \cdot 49$ & $0 \cdot 486$ \\
Species $\times$ treatment & 2 & $1 \cdot 66$ & $5 \cdot 98$ & $0 \cdot 003$ \\
Size $\times$ treatment & 2 & $0 \cdot 34$ & $1 \cdot 23$ & $0 \cdot 249$ \\
Species $\times$ size $\times$ treatment & 2 & $0 \cdot 21$ & $0 \cdot 76$ & $0 \cdot 469$ \\
Error & 573 & $0 \cdot 28$ & & \\
\hline
\end{tabular}

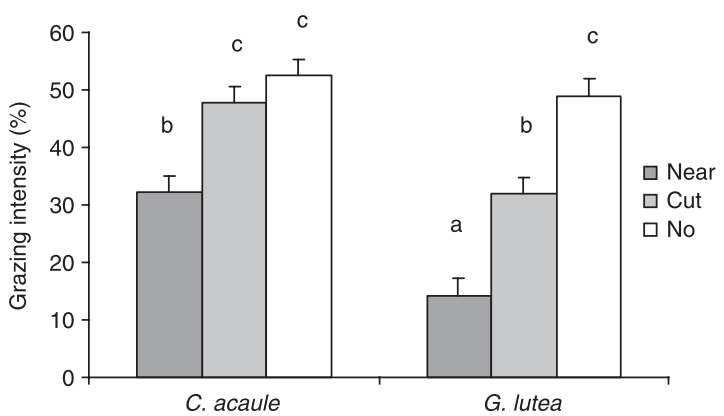

Fig. 1. Mean grazing intensity in $40-\mathrm{cm}$ circles around plots with tree saplings planted (i) $\pm 10 \mathrm{~cm}$ from the stems of the unpalatable plants Cirsium acaule or Gentiana lutea (near; dark bars); (ii) near removed (cut at soil level) unpalatable plants (cut; grey bars); and (iii) with no unpalatable plant nearby (no; white bars). Different letters indicate significant differences in grazing intensities $(P<0 \cdot 01$, Tukey HSD tests).

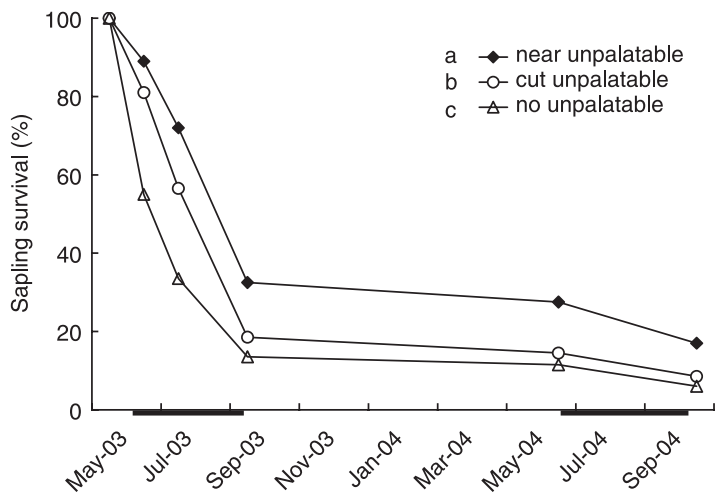

Fig. 2. Percentage survival of tree saplings transplanted near unpalatable plants (black diamonds), near cut unpalatable plants (open circles) and with no unpalatable plants (open triangles), over 2 years. Grazing seasons (black lines) and date of measurement are indicated in the figure. Different letters indicate significant differences between treatments over the entire study period (Cox regression, $-2 \log$ likelihood 6190.82, d.f. $2, P<0 \cdot 001)$.

(53.4\%), $131(21 \cdot 5 \%), 107(17 \cdot 6 \%)$ and $63(10 \cdot 6 \%)$ after 52, 66, 129, 373 and 498 days, respectively (Fig. 2). Most saplings (194) disappeared after the third and longest grazing rotation period, and the lowest mortality was during winter (24). Results of the Cox regression 
Table 2. Analysis of deviance for the effects of the predictor variables size, species and treatment and their interactions on sapling survival after one and two grazing seasons (GLM, binomial distribution, logit link)

\begin{tabular}{|c|c|c|c|c|c|c|}
\hline \multirow[t]{2}{*}{ Source } & \multicolumn{3}{|c|}{ Survival after 1 year } & \multicolumn{3}{|c|}{ Survival after 2 years } \\
\hline & d.f. & Deviance & $P$ & d.f. & Deviance & $P$ \\
\hline Size & 1 & $6 \cdot 22$ & $0 \cdot 013$ & 1 & $7 \cdot 61$ & $0 \cdot 006$ \\
\hline Species & 1 & $2 \cdot 96$ & $0 \cdot 085$ & 1 & $1 \cdot 07$ & $0 \cdot 301$ \\
\hline Treatment & 2 & $16 \cdot 16$ & $0 \cdot 000$ & 2 & $11 \cdot 44$ & $0 \cdot 003$ \\
\hline Species $\times$ size & 1 & $9 \cdot 21$ & $0 \cdot 002$ & 1 & $5 \cdot 95$ & $0 \cdot 015$ \\
\hline Species $\times$ treatment & 2 & $4 \cdot 31$ & $0 \cdot 116$ & 2 & $7 \cdot 72$ & $0 \cdot 021$ \\
\hline Size $\times$ treatment & 2 & $1 \cdot 55$ & $0 \cdot 461$ & 2 & $8 \cdot 15$ & $0 \cdot 017$ \\
\hline Species $\times$ Size $\times$ treatment & 2 & $0 \cdot 79$ & 0.673 & 2 & $3 \cdot 40$ & $0 \cdot 182$ \\
\hline Residual & 590 & $358 \cdot 52$ & & 575 & $235 \cdot 97$ & \\
\hline Total & 601 & $399 \cdot 73$ & & 586 & $281 \cdot 31$ & \\
\hline
\end{tabular}
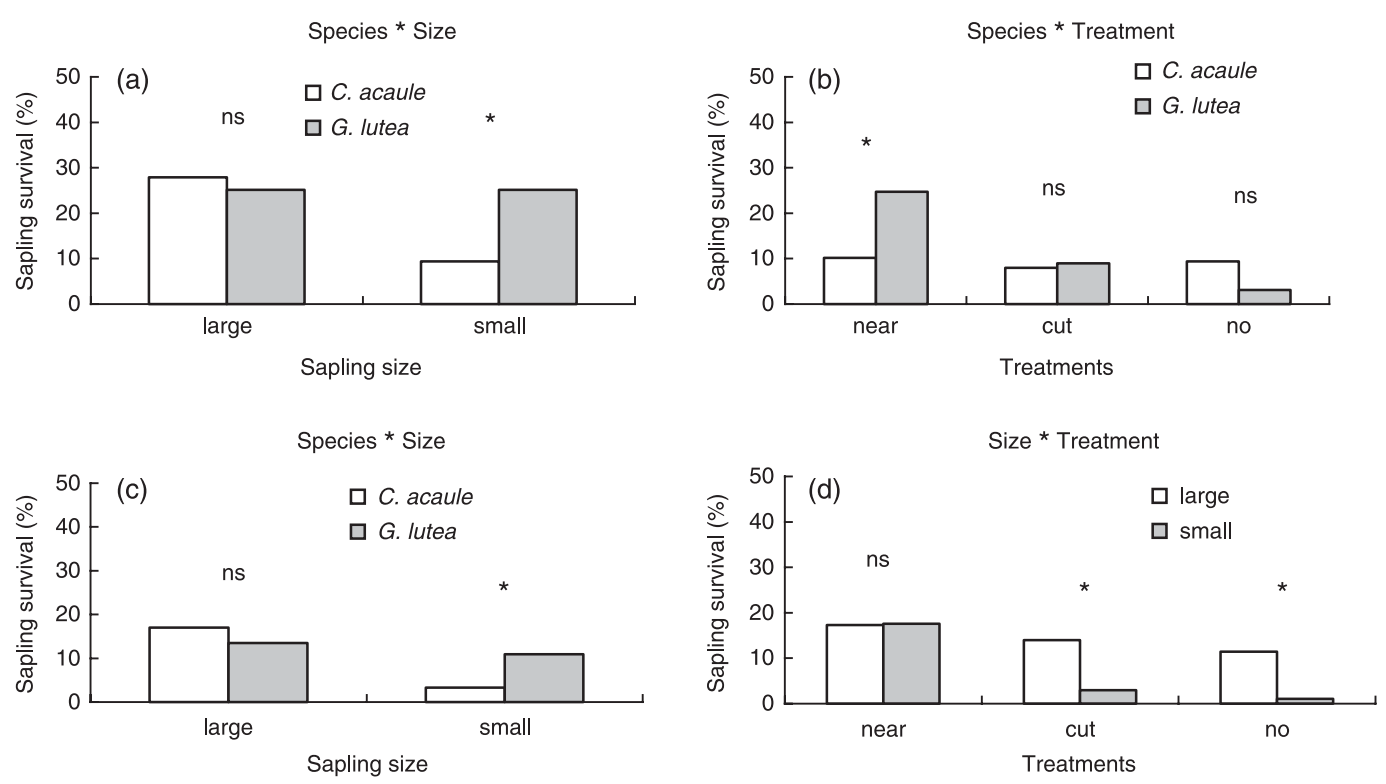

Fig. 3. Directions of the significant interactions for sapling survival after 1 (a), and 2 years (b-d). ${ }^{*} P<0 \cdot 05 ; \mathrm{ns}, P>0 \cdot 05$.

showed highly significant differences in sapling survival rates between all three treatments $(-2 \log$ likelihood $6190 \cdot 82$, d.f. $2, P<0 \cdot 001)$. Sapling survival was consistently significantly highest in the plots with unpalatable plants and significantly lowest in the plots without unpalatable plants over the entire period of the study (Wald statistic 30.46, $P<0 \cdot 001$ ). The difference between the cut and no unpalatable plots decreased gradually until the end of the first grazing season.

Results of the GLM showed that the factors size, treatment and species $\times$ size had significant effects on sapling survival after the first grazing season (Table 2). Overall, survival was significantly higher for the large saplings $(26 \%)$ than for the small saplings $(17 \%)$. Further, sapling survival after the first grazing season was significantly different between all three treatments, being highest in plots with unpalatables (33\%), lower in plots with cut unpalatables (19\%) and lowest in plots without unpalatables (14\%) (Bonferroni test, $P<0 \cdot 05$ ). The interaction was explained by a significantly lower survival of small saplings in the Cirsium plots compared with Gentiana plots, while survival of the large saplings was not different between species (Fig. 3a).

The factors size, treatment, species $\times$ size, species $x$ treatment and size $x$ treatment significantly affected sapling survival after two grazing seasons (Table 2). Again, survival was significantly higher for the large saplings (14\%) compared with the small saplings $(7 \%)$, and significantly (Bonferroni test, $P<0 \cdot 05$ ) higher in plots with unpalatable plants $(18 \%)$ compared with the plots with cut unpalatables $(9 \%)$ and without unpalatable plants $(6 \%)$. The latter two were not significantly different. Figure $3 \mathrm{~b}-\mathrm{d}$ shows the directions of the significant interactions: sapling survival was significantly lower for small saplings in Cirsium plots than in Gentiana plots, but there was no difference between species for the large saplings (Fig. 3c). Sapling survival was significantly higher in plots with Gentiana than in plots with Cirsium, but there was no difference between species for the other treatments (Fig. 3b). Further, large saplings survived significantly better than the small saplings in the plots with cut unpalatables and without unpalatables, but not in plots with unpalatable plants (Fig. 3d). 
(a)

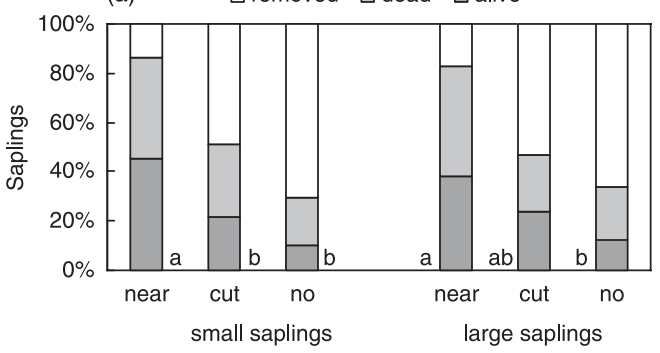

G. lutea treatments

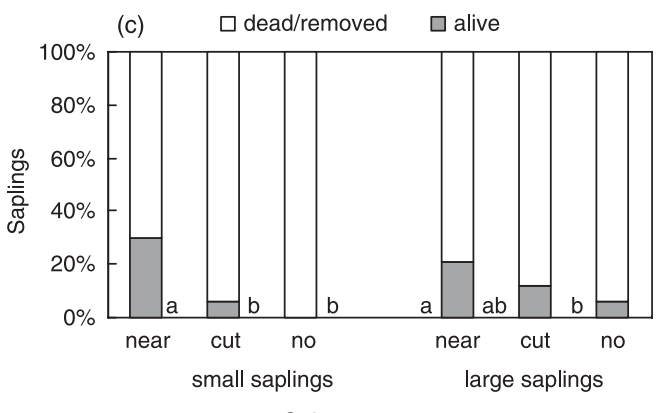

G. lutea treatments (b) $\square$ removed $\square$ dead $\square$ alive

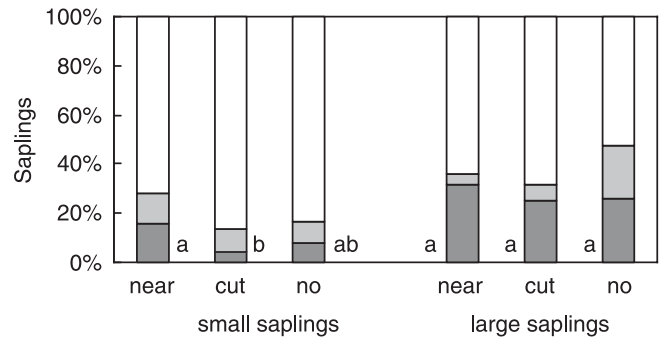

C. acaule treatments

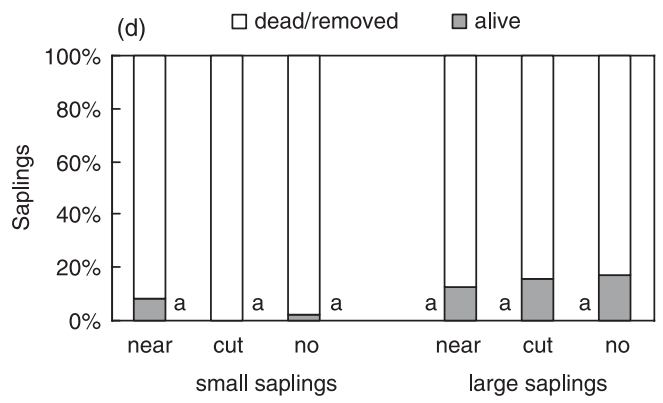

C. acaule treatments

Fig. 4. Percentage of removed, dead and living tree saplings after one $(a, b)$ and two $(c, d)$ grazing seasons for each combination of treatment and size and separately for Gentiana lutea (a, c) and Cirsium acaule (b, d) treatments. Different letters indicate significant differences between treatments for each species per sapling size $(P<0 \cdot 05$, Bonferroni tests).

The ratio of removed to dead saplings was significantly affected by unpalatable species, treatment and their interaction (deviance ratios, respectively: $35 \cdot 47, P=$ $0.001 ; 6.36, P=0.002 ; 5 \cdot 78, P=0.003)$. The ratio removed to dead saplings was higher for Cirsium (0.87) than for Gentiana ( $0 \cdot 56)$, and Bonferroni tests revealed that this ratio only differed significantly between Gentiana treatments, being significantly lower in the plots with Gentiana $(0 \cdot 26)$ compared with plots with cut (0.66) and without Gentiana (0.77). Therefore, except for saplings in plots with Gentiana, removal by herbivores was the most important cause of death.

\section{SAPLING GROWTH}

On average, the height growth of the saplings after 1 and 2 years was $3 \%( \pm 26 \mathrm{SD})$ and $11 \%( \pm 33 \mathrm{SD})$, respectively, but we did not find significant effects of species, treatment or their interaction. Hence no evidence was found for competition effects of unpalatable plants on the tree saplings, but sample sizes of 126 and 62 may have been too small to detect a potential difference after 1 and 2 years of growth.

\section{Discussion}

\section{ASSOCIATIONAL RESISTANCE}

In this study, we found clear empirical evidence for the existence of associational resistance in wooded pastures, confirming suggestions based on descriptive studies (Smit et al. 2005). Over a period of 2 years, overall survival of $P$. abies saplings was significantly higher when planted near unpalatable plants than when planted near cut unpalatable plants or in the open (without any unpalatable plants). These findings correspond with a significantly lower grazing intensity near unpalatable plants. Hence, we propose that avoidance of the unpalatable plants by cattle caused the observed differences in sapling survival. As the final survival of the Picea saplings did not reveal significant differences between the cutting and the control treatments, it appears that the effects of soil and microenvironment did not play an important role in sapling survival in this study.

\section{DIFFERENCES BETWEEN THE TWO} UNPALATABLE SPECIES

Although we found an overall facilitative effect of the unpalatable plants for the survival of the transplanted tree saplings, effects of Gentiana were stronger than of Cirsium for both sapling sizes (Fig. 4). Several hypotheses may be raised for these observed differences. First, Gentiana is more apparent and therefore easier to detect and avoided by herbivores than Cirsium. Secondly, cattle may avoid Gentiana more than Cirsium because of a difference in unpalatability. We did not observe cattle eating Gentiana, except for its flowers. In contrast, young leaves of Cirsium were quite frequently grazed, indicating higher palatability of the physically defended Cirsium. Thirdly, the biotic and abiotic environments of the two species may differ. The larger Gentiana could offer better protection against direct sunlight and drought, creating a more shaded and moist environment for the tree saplings. In addition, although not observed in this study, plant species 
composition around both unpalatable plants could vary, thereby affecting the attractiveness of the site to cattle and the performance of the tree saplings. Finally, soil conditions (depth, nutrients, moisture) may differ between the two species, although height of Picea saplings did not differ between unpalatable species.

\section{EFFECTS OF TREE SAPLING SIZE}

Sapling size had significant effects on survival after one and two grazing seasons. Overall, the survival of large saplings was higher than that of small saplings, and large saplings seemed less affected by the treatments (Fig. 3d). This indicates that the first 2 years are the most critical stage for establishment of $P$. abies in wooded pastures. Picea abies is browsed by cattle but is not a preferred food source; hence, small saplings are probably browsed by chance together with more tasty surrounding focal species. Larger saplings may be browsed less because they are more obvious to herbivores (Rao et al. 2003).

\section{MORTALITY}

Sapling mortality is often caused by additive rather than individual processes (e.g. trampling may increase drought stress; Ibanez \& Schupp 2001). As most tree saplings planted away from or near to cut unpalatable plants were completely removed and killed by cattle, grazing was the most important factor for sapling mortality. Tree saplings were usually completely uprooted by cattle. Naturally established tree saplings might be less prone to removal by cattle, because of better-developed root systems. As P. abies is browsing resistant and grows back after frequent browsing, we may have underestimated the potential of tree saplings to survive browsing and grazing in this study.

\section{SAPLING GROWTH AND COMPETITION EFFECTS}

Better growth of the unprotected (cut or no unpalatable plants) vs. the protected tree saplings (near unpalatables) would indicate competitive effects of the unpalatable plants. However, our analyses showed no differences in height of the saplings between treatments or species. These results are in contrast to findings of others studies reporting reduced growth of tree saplings in the proximity of the nurse shrubs (Meiners \& Gorchov 1998; Rousset \& Lepart 2000). It is possible that in our studied system the competition with unpalatable plants does not differ much from that with vegetation without unpalatables (i.e. mainly grasses). In contrast, the relatively high sapling mortality (other than as a result of removal by cows) near Gentiana in particular after the first grazing season could be an effect of increased competition (Fig. 4a). We acknowledge that we did not evaluate competition for light between the treatments. Further, the relatively short study time and low statistical power may well explain the lack of difference in sapling growth between treatments.

\section{DYNAMICS OF WOODED PASTURES}

Our findings indicate that unpalatable plants can enhance tree regeneration in wooded pastures and demonstrate the importance of associational resistance for the dynamics of these ecosystems. Given the low survival of unprotected 1-year-old tree saplings, protection against cattle by unpalatable plants facilitates their establishment. Once established, protection against cattle seems to become less important. We found higher survival of older tree saplings, and these established trees will eventually out-compete their nurse plants. At our site, this was demonstrated by the presence of solitary small trees, grown taller than their initial facilitators and surviving the continuous browsing by cattle (Smit et al. 2005).

In Mediterranean areas, transplanting tree saplings under naturally existing nurse shrubs is a successful alternative technique for reforestation, offering both economic and ecological advantages above the more traditional large-scale clear-cutting and planting technique (Castro et al. 2002). Our results show that transplanting tree saplings near unpalatable plants could also be an alternative technique for reforestation programmes in intensively and overgrazed wooded pastures. On the other hand, removal of unpalatable plants and shrubs might prevent or slow down undesired tree regeneration in extensively grazed areas.

Pastural abandonment and intensification of agricultural management are expected to continue in the near future (Tilman et al. 2002), with drastic consequences for many ecosystems. Both intensification and abandonment of grazing may lead to an increase of unpalatable plants in grasslands (Callaway, Kikvidze \& Kikvidze 2000) and wooded pastures. This increase of unpalatable plants could speed up the succession to trees in wooded pastures and lead to a rapid closing of the canopy, with an expected loss of biodiversity.

\section{Acknowledgements}

The National Centre of Competence in Research (NCCR) Plant Survival, research program of the Swiss National Science Foundation, funded this project. We thank Mr Ducrot and the Parc Regional de Vaux for the use of their land, J. Kalwij for creating useful maps of the study site, and E. Hesse, L. and R. Handley, R. Smit and T. Ekamper for their fruitful discussions and help during fieldwork. Comments by two anonymous referees and editors greatly improved an earlier version of the manuscript.

\section{References}

Arevalo, J.R. \& Fernandez-Palacios, J.M. (2003) Spatial patterns of trees and juveniles in a laurel forest of Tenerife, Canary Islands. Plant Ecology, 165, 1-10. 
Atstatt, P.R. \& Odowd, D.J. (1976) Plant defense guilds. Science, 193, 24-29.

Bakker, E.S., Olff, H., Vandenberghe, C., De Maeyer, K., Smit, R., Gleichman, J.M. \& Vera, F.W.M. (2004) Ecological anachronisms in the recruitment of temperate lightdemanding tree species in wooded pastures. Journal of Applied Ecology, 41, 571-582.

Berkowitz, A.R., Canham, C.D. \& Kelly, V.R. (1995) Competition vs facilitation of tree seedling growth and survival in early successional communities. Ecology, 76, 1156-1168.

Bokdam, J. \& Gleichman, J.M. (2000) Effects of grazing by free-ranging cattle on vegetation dynamics in a continental north-west European heathland. Journal of Applied Ecology, 37, 415-431.

Callaway, R.M., Kikvidze, Z. \& Kikvidze, D. (2000) Facilitation by unpalatable weeds may conserve plant diversity in overgrazed meadows in the Caucasus Mountains. Oikos, 89, 275-282.

Castro, J., Zamora, R. \& Hodar, J.A. (2002) Mechanisms blocking Pinus sylvestris colonization of Mediterranean mountain meadows. Journal of Vegetation Science, 13, 725-731.

Castro, J., Zamora, R., Hodar, J.A. \& Gomez, J.M. (2002) Use of shrubs as nurse plants: a new technique for reforestation in Mediterranean mountains. Restoration Ecology, 10, 297-305.

Choler, P., Michalet, R. \& Callaway, R.M. (2001) Facilitation and competition on gradients in alpine plant communities. Ecology, 82, 3295-3308.

Crawley, M.J. (1983) Herbivory. The Dynamics of Plant-Animal Interactions. Blackwell Scientific Publications, Oxford, UK.

Ibanez, I. \& Schupp, E.W. (2001) Positive and negative interactions between environmental conditions affecting Cercocarpus ledifolius seedling survival. Oecologia, 129, $543-550$.

Kuiters, A.T. \& Slim, P.A. (2003) Tree colonisation of abandoned arable land after 27 years of horse-grazing: the role of bramble as a facilitator of oak wood regeneration. Forest Ecology and Management, 181, 239-251.

Meiners, S.J. \& Gorchov, D.L. (1998) Effects of distance to Juniperus virginiana on the establishment of Fraxinus and Acer seedlings in old fields. American Midland Naturalist, 139, 353-364.

Milchunas, D.G. \& Noy-Meir, I. (2002) Grazing refuges, external avoidance of herbivory and plant diversity. Oikos, 99, 113-130.
Munzbergova, Z. \& Ward, D. (2002) Acacia trees as keystone species in Negev desert ecosystems. Journal of Vegetation Science, 13, 227-236.

Nunez, C.I., Aizen, M.A. \& Ezcurra, C. (1999) Species associations and nurse plant effects in patches of highAndean vegetation. Journal of Vegetation Science, 10, 357-364.

Olff, H., Vera, F.W.M., Bokdam, J., Bakker, E.S., Gleichman, J.M. \& de Maeyer, K.\& Smit, R. (1999) Shifting mosaics in grazed woodlands driven by the alternation of plant facilitation and competition. Plant Biology, 1, 127-137.

Pages, J.P. \& Michalet, R. (2003) A test of the indirect facilitation model in a temperate hardwood forest of the northern French Alps. Journal of Ecology, 91, 932-940.

Pott, R. \& Hüppe, J. (1991) Die Hudelandschaften Nordwestdeutschlands. Landschaftsverbamd Westfalen-Lippe, Veröffentlichung der Arbeitsgemeinschaft für biologischökologische Landeserforschung, ABÖL, No. 89. Westfälisches Museum für Naturkunde, Münster, Germany.

Rao, S.J., Iason, G.R., Hulbert, I.A.R., Elston, D.A. \& Racey, P.A. (2003) The effect of sapling density, heather height and season on browsing by mountain hares on birch. Journal of Applied Ecology, 40, 626-638.

Rousset, O. \& Lepart, J. (1999) Shrub facilitation of Quercus humilis regeneration in succession on calcareous grasslands. Journal of Vegetation Science, 10, 493-502.

Rousset, O. \& Lepart, J. (2000) Positive and negative interactions at different life stages of a colonizing species (Quercus humilis). Journal of Ecology, 88, 401-412.

Smit, C., Béguin, D., Buttler, A. \& Müller-Schärer, H. (2005) Safe sites for tree regeneration in wooded pastures: a case of associational resistance? Journal of Vegetation Science, 16, 209-214.

Tilman, D., Cassman, K.G., Matson, P.A., Naylor, R. \& Polasky, S. (2002) Agricultural sustainability and intensive production practices. Nature, 418, 671-677.

Tirado, R. \& Pugnaire, F.I. (2003) Shrub spatial aggregation and consequences for reproductive success. Oecologia, 136, 296-301.

Vera, F.W.M. (2000) Grazing Ecology and Forest History. CAB International, Waltingford, UK.

Received 21 June 2005; final copy received 23 November 2005 Editor: Yvonne Buckley 